\title{
Nonneuronal Cholinergic System in Breast Tumors and Dendritic Cells: Does It Improve or Worsen the Response to Tumor?
}

\author{
Marisa Vulcano, ${ }^{1}$ María Gabriela Lombardi, ${ }^{2}$ and María Elena Sales ${ }^{2}$ \\ ${ }^{1}$ Laboratorio de Inmunofarmacología, Segunda Cátedra de Farmacología, Facultad de Medicina, \\ Universidad de Buenos Aires (UBA), C1121ABG Ciudad de Buenos Aires, Argentina \\ ${ }^{2}$ Laboratorio de Inmunofarmacología Tumoral, Centro de Estudios Farmacológicos y Botánicos (CEFYBO)-CONICET, \\ UBA, C1121ABG Ciudad de Buenos Aires, Argentina
}

Correspondence should be addressed to Marisa Vulcano; marisavulcano@yahoo.com

Received 30 September 2013; Accepted 20 October 2013

Academic Editors: T. W. Grunt and F. Iovino

Copyright (C) 2013 Marisa Vulcano et al. This is an open access article distributed under the Creative Commons Attribution License, which permits unrestricted use, distribution, and reproduction in any medium, provided the original work is properly cited.

Besides being the main neurotransmitter in the parasympathetic nervous system, acetylcholine (ACh) can act as a signaling molecule in nonneuronal tissues. For this reason, ACh and the enzymes that synthesize and degrade it (choline acetyltransferase and acetylcholinesterase) as well as muscarinic (mAChRs) and nicotinic receptors conform the non-neuronal cholinergic system (nNCS). It has been reported that nNCS regulates basal cellular functions including survival, proliferation, adhesion, and migration. Moreover, nNCS is broadly expressed in tumors and in different components of the immune system. In this review, we summarize the role of $\mathrm{nNCS}$ in tumors and in different immune cell types focusing on the expression and function of $\mathrm{mAChRs} \mathrm{in} \mathrm{breast} \mathrm{tumors}$ and dendritic cells (DCs) and discussing the role of DCs in breast cancer.

\section{The Nonneuronal Cholinergic System}

Organic compounds were formed at the very beginning of the earth, and acetylation of molecules is one of the most common reactions in nature. Because of this, it could be probable that acetylcholine ( $\mathrm{ACh}$ ) exists since the prebiotic period. This can be proved by the fact that $\mathrm{ACh}$ is present in bacteria, blue-green algae, yeast, fungi, protozoa, and primitive plants [1]. In addition to its presence in neurons, $\mathrm{ACh}$ is expressed in pro- and eukaryotic nonneuronal cells. Thus, ACh works as a signaling molecule in nonneuronal cells and tissues, before its neuronal function spans. For these reasons, Wessler et al. [2] have introduced the term "nonneuronal ACh" and "nonneuronal cholinergic system" (nNCS) to indicate the presence of ACh in cells independent of neurons. In turn, Grando [3] introduced the term "universal cytotransmitter", which denotes the involvement of ACh in the regulation of basic and frequently nervous-independent cell functions like proliferation, differentiation, organization of the cytoskeleton, locomotion, secretion, ciliary activity, and local release of mediators (i.e., nitric oxide and proinflammatory cytokines).

In addition, $\mathrm{ACh}$ is the main neurotransmitter in the neuronal cholinergic system. The latter is conformed by central and peripheral neurons. ACh is synthesized by preganglionic fibers of the sympathetic and parasympathetic autonomic nervous system and by postganglionic parasympathetic fibers. The organization of a cholinergic neuron and synapse is well known. In cholinergic neurons the synthesis of ACh occurs within the nerve terminal via choline acetyltransferase (ChAT) enzyme. ACh is accumulated in vesicles and is released by exocytosis to allow a highly effective neurotransmission. The presence of nicotinic acetylcholine receptors (nAChRs) or muscarinic acetylcholine receptors (mAChRs) and high acetylcholinesterase (AChE) activity very close to the synapse are needed for the rapid and short lasting action of ACh as neurotransmitter [4]. Meanwhile, in the nNCS, 
ACh liberation occurs just after its synthesis, without being stored in vesicles. Previous studies performed in placenta indicate that the release of $\mathrm{ACh}$ in nonneuronal cells is mediated by the family of organic cation transporters (OCT) [5]. Three isoforms of OCT have been described: OCT1, OCT2, and OCT3, and they are differentially expressed in tissues and organs (i.e., OCT1 and OCT3 are expressed in placenta and human epithelia). ACh actions are slow and continuous in nNCS and AChE activity is lower than in neuronal cholinergic system [6].

In summary, overwhelming evidence indicates that cells outside the neuronal system synthesize, contain, and release ACh. This property has been identified not only for the abundant majority of human cells but also in other mammals, lower invertebrates, protozoa, plants, fungi, blue-green algae, and even bacteria [4].

\section{2. mAChRs and nAChRs Signal Transduction Pathways}

mAChRs belong to the family of G-protein coupled receptors. Five different subtypes have been genetically identified: $M_{1}-$ $\mathrm{M}_{5}$ [7]. The coupling of mAChRs to their cellular effector systems is mediated via heterotrimeric G-proteins that are composed by one $\alpha-, \beta$-, and $\gamma$-subunit each and are classified virtue to their $\alpha$-subunit in four families: $\mathrm{G} \alpha \mathrm{s}$, $\mathrm{G} \alpha \mathrm{i} / \mathrm{o}, \mathrm{G} \alpha \mathrm{q}$, and $\mathrm{G} \alpha 12$ [8]. Receptor activation results in the dissociation of the heterotrimeric G-protein into its $\alpha$-and $\beta / \gamma$-subunits, and the latter subunits are tightly bound and display one functional unity. Both the $\alpha$-subunit and the $\beta / \gamma$ subunit are involved in the transduction of muscarinic signals (Figure 1). Thus, $M_{1}, M_{3}$, and $M_{5}$ receptors couple preferentially to $\mathrm{Gq}$ proteins, whereas $\mathrm{M}_{2}$ and $\mathrm{M}_{4}$ subtypes interact with the Gi/o family of proteins. One important target activated by $\mathrm{Gq}$ represents phospholipase $\mathrm{C}$ mediating the hydrolysis of phosphatidylinositol 4,5-bisphosphate to generate inositol 1,4,5-triphosphate $\left(\mathrm{IP}_{3}\right)$ and diacylglycerol. Gi/o proteins inhibit adenylyl cyclase activity, as well as prolong potassium channel, nonselective cation channel and transient receptor potential channels opening [9-11]. mAChRs have also been shown to regulate a diverse array of signaling intermediates that are not considered as classical (Figure 1). Thus, both $\mathrm{G} \alpha \mathrm{i} / \mathrm{o}$ - and $\mathrm{G} \alpha \mathrm{q} / 11$-coupled subfamily members exert cytoskeletal effects through activation of the small GTPase Rho and downstream effectors include phosphoinositide-3 kinases, nonreceptor tyrosine kinases, and mitogen-activated protein kinases (MAPKs) [12].

$\mathrm{nAChRs}$ are a family of ligand-gated, pentameric ion channels. The main function of this receptor family is to transmit ACh signals at neuromuscular junctions and in the central and peripheral nervous systems. In humans, 16 different nAChRs subunits $(\alpha 1-7, \alpha 9-10, \beta 1-4, \delta, \varepsilon$, and $\gamma$ ) have been identified [13]. These subunits have the potential to form a large number of homo- and heteropentameric receptors with distinct properties and functions. Among the 16 subunits, only the $\alpha 1, \alpha 7$, and $\alpha 9$ subunits bind an antagonist derived from snake venom, $\alpha$-bungarotoxin. Most neuronal nAChR channels, like muscle nAChR channels, are cation specific but do not distinguish readily among different cations. In particular, neuronal nAChRs associated channels allow $\mathrm{Na}^{+}, \mathrm{K}^{+}$, and $\mathrm{Ca}^{2+}$ transfer [13].

\section{Expression and Function of Cholinergic Receptors in Normal and Transformed Tissues and Cells}

The diversity of signaling pathways mediated by ACh effects explains the plethora of cholinergic effects in different types of nonneuronal cells and provides a basis for understanding the biology of normal and malignant cells. Normal signaling along the $\mathrm{ACh}$ axis is vital for growth and differentiation of human epithelial cells. The biological effects of ACh in nonneuronal cells are finely tuned to the regulation of each phase of the cell cycle via the intracellular signaling pathways coupled by each ACh receptor subtype. Each biological effect of $\mathrm{ACh}$ in the epithelium is determined by a unique combination of cholinergic receptors [14]. The expression of the muscarinic receptors $M_{1}, M_{2}$, and $M_{3}$ have been described in airways and lung tissues of most mammals including humans. $M_{1}$ receptors appear to be expressed particularly in peripheral lung tissue and alveolar wall but could not be detected in larger airways [15]. nAChRs have been also identified in the lung and airway epithelial cells. At present, clear evidence exits indicating that the activation of nNCS is involved in the control of epithelial cell adhesion, in cell-cell interactions and proliferation, and, thus, in the regulation of epithelial layer integrity, as well as in the interaction between airways and immune cells [14].

In addition to their physiological functions, $\mathrm{mAChRs}$ and nAChRs have been also implicated in malignant processes in airways. The binding of endogenous ACh to both nAChRs and mAChRs stimulates the growth of both small cell and nonsmall cell lung carcinomas. The analysis of 28 squamous cell lung carcinomas showed increased levels of both $\alpha 5$ and $\beta 3$ nAChRs mRNA and ACh which were associated with increased levels of ChAT and decreased amounts of AChE mRNAs. Thus, cholinergic signaling is broadly increased in this type of tumor due to the high levels of expression of both receptors and ligands [16].

The cholinergic circuitry of the enteric system is extensive and mediates motility (muscular) and secretory (mucosal) reflexes, in addition to intrinsic sensory and vascular reflexes. The capacity of ACh to mediate multiple physiologically significant intestinal reflexes is largely due to the presence of multiple sites of neuronal and nonneuronal release and reception within the intestine. The five subtypes of mAChRs have been identified in epithelia, muscle, and nerves, and $M_{3}$ receptor subtype is the major regulator of motility and secretion in these tissues. This receptor has been also involved in the regulation of colon cancer cells proliferation through the transactivation of the EGFR-ERK pathways [17].

Kurzen et al. [18] demonstrated an essential role for ACh and its receptors in epidermal physiology using organotypic cocultures. The blocking of nAChRs and mAChRs with mecamylamine and atropine, respectively, for 7-14 days results in the complete inhibition of epidermal differentiation and proliferation. nAChRs inhibition led to a less pronounced delay in epidermal differentiation and proliferation than that 


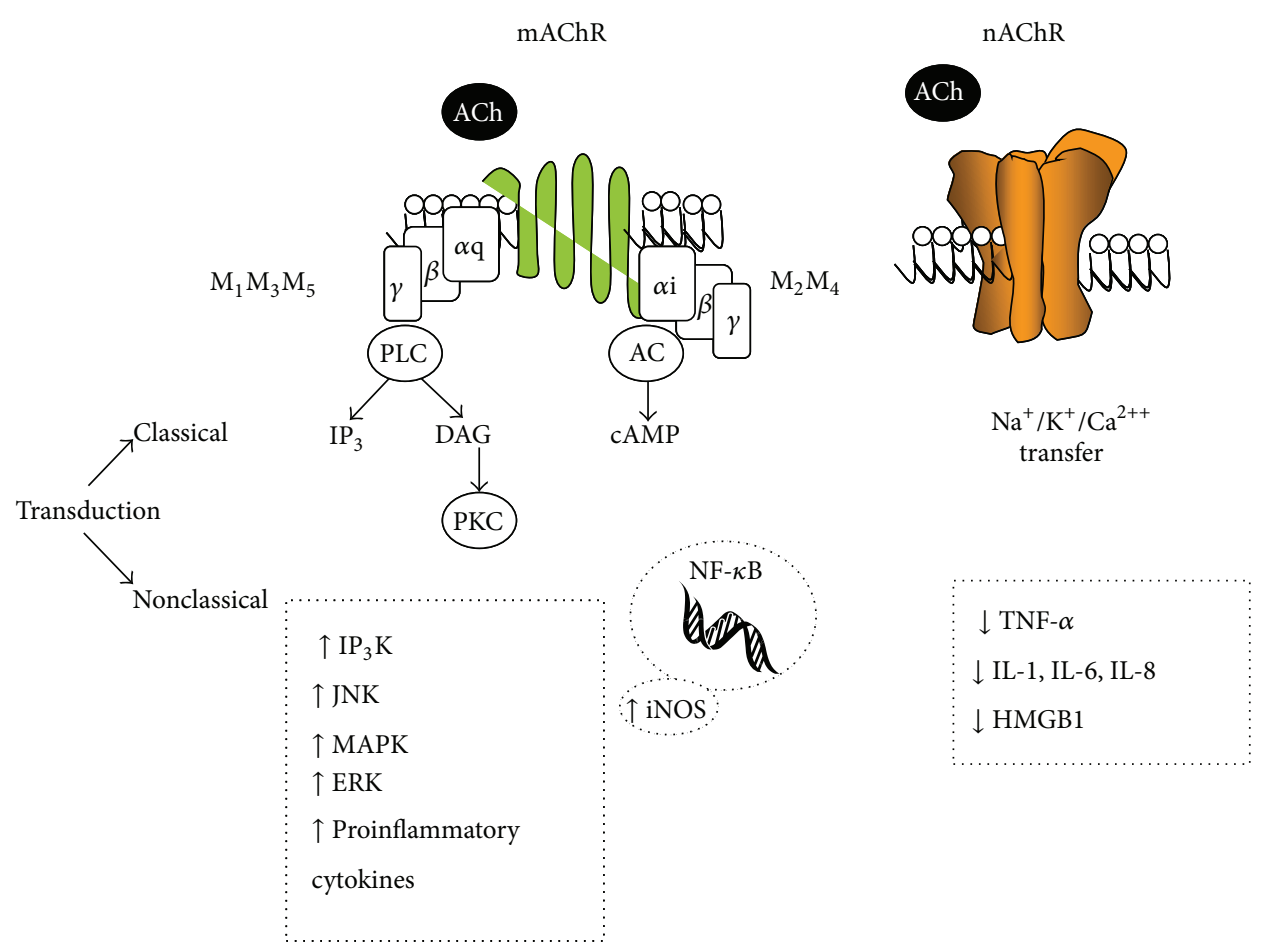

FIGURE 1: Subtypes of cholinergic receptors, transduction, and effects. Muscarinic acetylcholine receptors (mAChR); nicotinic acetylcholine receptors (nAChR); acetylcholine (ACh); phospholipase C (PLC); inositol triphosphate (IP 3 ); diacylglycerol (DAG); protein kinase C (PKC); adenylyl cyclase (AC); cyclic adenosine monophosphate (cAMP); inositol triphosphate kinase $\left(\mathrm{IP}_{3} \mathrm{~K}\right)$; Janus kinase (JNK); mitogen-activated protein kinase (MAPK); extracellular kinase (ERK); nuclear transcription factor- $\kappa \mathrm{B}$ (NF- $\kappa \mathrm{B}$ ); inducible nitric oxide synthase (iNOS); tumor necrosis factor alpha (TNF- $\alpha$ ); interleukin (IL); high mobility group box 1 (HMGB1).

obtained by blocking mAChRs with atropine, which was evidenced by reduced epithelial thickness and expression of terminal differentiation markers. In contrast, stimulation of nAChRs and mAChRs with cholinergic drugs results in a significant epithelium thickening accompanied by an improved epithelial maturation. Merkel cell carcinoma is a highly aggressive neuroendocrine carcinoma of the skin. More than one-third of the patients with this carcinoma will die, making it twice as lethal as malignant melanoma. Other authors have analyzed fifteen cases of primary nonmetastatic cutaneous Merkel cell carcinoma and detected the expression of $\beta 2 \mathrm{nAChR}$ and $\mathrm{mAChR}$ subtypes 3 and 5 which could be linked to malignant cell proliferation and migration [19].

nAChRs and mAChRs are well-known modulators of brain functions. Previous works have indicated that mAChRs are expressed in primary cultures of oligodendrocytes and that their activation promotes cell proliferation via MAPKs. It has been also demonstrated that mAChRs activation increases cell survival and differentiation [20, 21]. Other authors detected the expression of $\mathrm{M}_{3}$ receptors in $\mathrm{SH}$ SY5Y human neuroblastoma cells. The stimulation of these receptors leads to an increase in intracellular calcium levels and $\mathrm{IP}_{3}$ formation in these cells, both events are known to trigger cell proliferation [22].

3.1. mAChRs Expression and Function in Breast Cancer. Unlike other tissues, normal breast tissues do not express cholinergic receptors. In our laboratory, we have confirmed that normal murine mammary cells NMuMG, as well as MCF-10A cells, derived from normal human breast, show no-positive immunostaining by Western blot or by specific radio-ligand binding for any subtype of mAChRs [23-25]. In addition, we have also observed, by using immunoblotting techniques, that $\mathrm{mAChRs}$ were absent in homogenates of surgical samples obtained from normal human mammary tissue [25]. On the contrary, we found that mAChRs are constitutively expressed in three different cell lines LM2, LM3, and LMM3 derived from murine mammary adenocarcinomas that spontaneously arose in BALB/c mice. Stimulation of these functional receptors potentiates different stages of tumorigenesis, such as cell proliferation, migration, angiogenesis, and tumor growth in vivo [26-28]. We observed that LMM3 cells, which were obtained from a lung metastasis of M3 tumor, upregulate mAChRs expression up to 50-fold in comparison with LM3 cells, suggesting that mAChRs could modulate the metastatic ability of tumor cells [27]. As it was shown in other tumor cell types (i.e., lung, colon, or melanoma), LMM3 tumor cells exhibit a major expression of $\mathrm{M}_{3}$ subtype, which mainly mediates the proliferative action induced by the cholinergic agonist carbachol. Similarly, MCF-7 cells, derived from an estrogen-dependent human mammary adenocarcinoma, express the $M_{3}$ and $M_{4}$ subtypes of $m A C h R s$ (Figure 2) [29]. Stimulation of $\mathrm{mAChRs}$ with carbachol potentiates different steps of tumor progression. Particularly, we have observed that this agonist stimulates tumor proliferation. This action involves the participation of the $\mathrm{M}_{3}$ receptor signaling pathway which couples phospholipase $\mathrm{C} /$ nitric oxide synthase, protein kinase $\mathrm{C}$ effector enzymes. Carbachol also triggers 


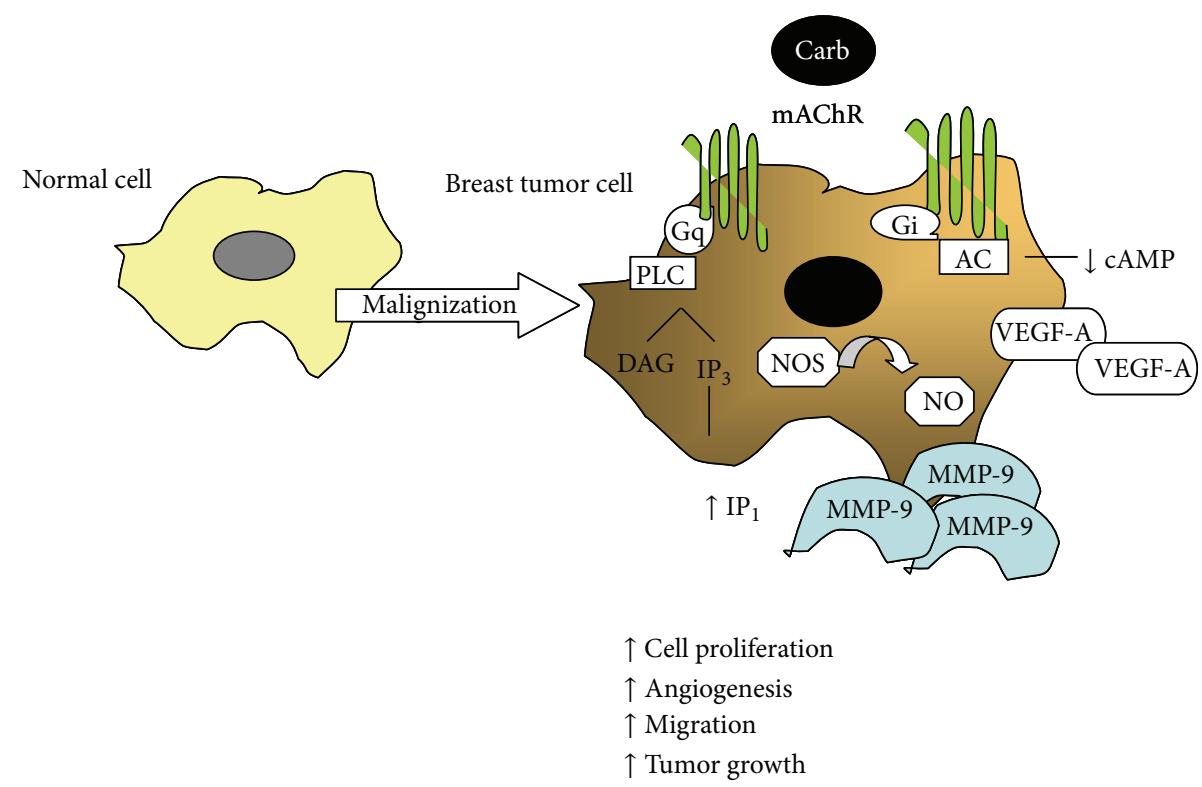

FIGURE 2: Expression and function of muscarinic acetylcholine receptors (mAChR) in breast tumor cells. Carbachol (Carb) stimulates mAChR and via Gq/11 protein increases phospholipase C (PLC) activity. This enzyme hydrolyzes phosphoinositides producing myoinositol 1,4,5trisphosphate $\left(\mathrm{IP}_{3}\right)$ and increases intracellular calcium levels which in turn activates nitric oxide synthase (NOS) that produces nitric oxide (NO). mAChRs also couple to Gi protein and inhibit the activation of adenilyl cyclase (AC) reducing cAMP formation. The agonist also increases synthesis and liberation of vascular endothelial growth factor-A (VEGF-A) and metalloproteinase-9 expression and activity in tumor cell supernatants.

nitric oxide synthesis and vascular endothelial growth factorA (VEGF-A) expression increasing blood vessels formation induced by mammary tumor cells in nude mice $[29,30]$. Recently, we have demonstrated that stimulation of mAChRs in MCF-7 cells increases tumor invasion by upregulating cell migration and metalloproteinase- 9 expression and activity in cell supernatants (Figure 2) [31].

\section{4. nNCS in Immune Cells}

ACh is synthesized by mononuclear leukocytes (MNL), bone marrow-derived dendritic cells (BMDCs), macrophages, skin mast cells, and human leukemic T-cell lines [32, 33]. It has been described that lymphocytes produce and secrete ACh depending on its differentiation and/or activation status [34]. Among T-cell subsets, $\mathrm{CD}^{+}$cells have a higher ability to synthesize $\mathrm{ACh}$ than $\mathrm{CD}^{+}$cells [35]. The synthesis of ACh in $\mathrm{T}$ cells is enhanced by activation of the $\mathrm{T}$ cell receptor (TCR)/CD3-mediated pathways, suggesting that the interaction of $\mathrm{T}$ cells with DCs during antigen presentation stimulates nonneuronal cholinergic activity. Besides the presence of ChAT activity, mRNA, and enzyme protein has also been detected in immune cells, such as $\mathrm{CD}^{+}$and $\mathrm{CD}^{+} \mathrm{T}$ cells, DCs, peripheral blood MNL, granulocytes, and mast cells [36-40]. Fujii et al. [35] demonstrated that the stimulation of $\mathrm{T}$ cells with phytohemagglutinin and dibutyryl cAMP enhances the synthesis and release of ACh and upregulates ChAT mRNA expression, suggesting that both drugs increase ChAT activity through the induction of ChAT gene transcription. The concentration of $\mathrm{ACh}$ is determined by the rates of release and diffusion across the plasma membrane and also by the hydrolysis mediated by
AChE; thus, this concentration should be much higher at the receptor sites than in the bulk plasma or conditioned media [33].

Additionally, the expression of the components of nNCS including choline high affinity transporter 1, ChAT, and vesicular acetylcholine transporter was detected in cells of the monocyte-macrophage lineage [41].

Most human MNL, T and B cells, thymocytes, human leukemic cell lines, and animal immune cells express different subtypes of cholinergic receptors [38]. All subtypes of mAChRs have been detected in cells of the monocytemacrophage lineage [41]. In freshly isolated CD $4^{+}$and $\mathrm{CD} 8^{+}$ T cells, mRNAs encoding $\alpha 5, \alpha 9, \alpha 10, \beta 1, \beta 2$, and $\beta 4$ nicotinic subunits and $M_{1}, M_{3}, M_{4}$, and $M_{5}$ receptors were detected, while the $\alpha 2$ subunit is present only in $\mathrm{CD}^{+} \mathrm{T}$ cells. However, the level of expression for each subtype of receptor appears to vary with immune status [42].

Regarding DCs, it was observed that human monocytederived DCs express only the $\alpha 7$ subunit of $\mathrm{nAChR}$ and murine bone marrow-derived DCs express different nAChRs [43]. On the other hand, it has been described that DCs isolated from surgically removed nasal mucosa express the $\mathrm{M}_{3}$ subtype [44]. Our results indicate that human monocytederived DCs express $M_{3}, M_{4}$, and $M_{5}$ receptors as well as ChAT and AChE in both immature and mature DCs [40].

\section{Role of nNCS in the Modulation of the Immune System}

ACh is able to modulate different functions in immune cells, such as the activation of $\mathrm{CD}^{+} \mathrm{T}$ cells $[37,45,46]$, the release of chemotactic factors from bovine alveolar macrophages 
trophic for neutrophils, monocytes, and eosinophils [47], and the release of leukotriene (LT) B4 from human and bovine alveolar macrophages, at less in part by $\mathrm{M}_{3}$ receptor activation [48]. It has been shown that stimulation of the nAChRs in peritoneal macrophages increased phagocytosis [49] whereas $\mathrm{mAChRs}$ activation promotes metabolic and phagocytic activity in neutrophils [50].

The equilibrium between pro- and anti-inflammatory cytokines and their sequential release may be one of the key factors that accounts for the severity of inflammatory responses. The presence of ACh can mediate opposite functions during inflammatory processes. Chronic stimulation of nAChRs suppresses the immune and inflammatory response causing T-cell anergy and decreased leukocyte migration. Similarly, the addition of ACh in the presence of AChE inhibitors in LPS-stimulated macrophages reduces the production of TNF- $\alpha$, IL-1 $\beta$, IL- 6 , and IL-18 through nAChR activation $[51,52]$. This anti-inflammatory effect is mediated, at least in part, by $\alpha 7 \mathrm{nAChR}$ given that is abolished in $\alpha 7 \mathrm{KO}$ mice $[53,54]$. Further reports propose that this effect could be also mediated by $\alpha 4$ and $\beta 2$ subunits in murine alveolar macrophages that do not express the $\alpha 7$ subunit [55].

On the other hand, acute activation of nAChRs in several cell types stimulates immune and inflammatory responses by a mechanism that includes the increase of intracellular calcium levels. Although activation of nAChRs on T cells stimulates protein tyrosine kinase activities and raises intracellular $\mathrm{Ca}^{2+}$ concentration no electrophysiological evidence supports the presence of nicotine-sensitive, ligand-gated cation channels on these cells. In contrast, $\alpha 7$-nAChR subunits can interact with the TCR/CD3 and raise intracellular $\mathrm{Ca}^{2+}$ through the TCR-associated signaling pathway. Some authors have suggested that this interaction could act as a costimulatory signal to trigger immune receptor activation [56].

Previous studies have shown that, in murine splenic $\mathrm{T}$ cells, nicotinergic stimulation upregulates interferon- $\gamma$ (IFN$\gamma$ ) liberation and downregulates interleukin IL-17 secretion, whereas muscarinic activation enhances IL-10 and IL-17 and inhibits INF- $\gamma$ secretion. Taken together, these results demonstrate the plasticity of the T-cell cholinergic system [42].

Stimulation of B cells with Staphylococcus aureus upregulates $\mathrm{M}_{5}$ receptor expression and $\mathrm{ACh}$ synthesis suggesting that the immunological activation of lymphocytes facilitates cholinergic signaling [57].

The use of knockout mice has allowed a better characterization of cholinergic receptors and their role in the modulation of the immune response. Fujii et al. [58] described that $\mathrm{M}_{1} / \mathrm{M}_{5} \mathrm{KO}$ mice, immunized with ovoalbumin, have lower serum concentrations of anti-OVA-specific $\operatorname{IgG}_{1}$ than wild-type mice. In addition, activated MNL obtained from these mice have lower AChE mRNA expression and exhibit a reduced secretion of proinflammatory cytokines (TNF- $\alpha$ and IL-6). These results suggest that $M_{1}$ and/or $M_{5}$ receptors are involved in the regulation of pro-inflammatory cytokines production, leading to the modulation of antibody synthesis.

Other pieces of evidence indicate that ACh not only is able to modulate inflammatory processes but also participates in the development of several diseases. Cystic fibrosis is associated with enhanced infections and it has been reported that the content of ACh is significantly reduced in the airways and peripheral leucocytes in fibrotic patients revealing a dysfunction in nNCS in this disease [59]. ACh limits the migration of peripheral granulocytes. Wessler et al. [60] have described that this effect is impaired in cystic fibrosis most likely because of a reduced endogenous cholinergic tone.

Myasthenia gravis is a B-cell-mediated, T-cell-dependent, antibody-mediated autoimmune disorder in which nAChRs at the neuromuscular junction are the major autoantigens. In this illness, the proliferation of cholinergic receptors-reactive lymphocytes is increased and anticholinergic receptor IgG and inflammatory cytokine levels (IFN- $\gamma$, TNF- $\alpha$, IL- 6 , and IL-17) are enhanced [61, 62].

\section{Cholinergic Modulation of DCs Function}

DCs are the most potent professional antigen presenting cells which can uptake, process, and present different types of antigens, including tumor antigens $[63,64]$, to antigenspecific naïve $\mathrm{T}$ cells. DCs, which originated from bone marrow hematopoietic progenitor cells, can be found in immature or semimature state in different nonlymphoid tissues and organs. In this state DCs act as sentinels of the immune system by efficiently capturing and processing foreign antigens. In the presence of a "danger signal" (such as infection or inflammation), DCs shift from an antigencapturing mode to a T-cell sensitizing mode, a phenomenon called "maturation" which is usually associated with their migration to secondary lymphoid tissues where they provide signals 1-3 to T lymphocytes [63].

It has been reported that activation of the nAChRs modulates the function of DCs. Human monocyte-derived DCs express the $\alpha 7 \mathrm{nAChR}$ while murine bone marrowderived DCs express different nAChRs [43]. Nicotine may have effects on DCs activity by regulating their local cytokine environment and consequently modify indirectly their function in primary specific immune responses [50]. Moreover, supporting an anti-inflammatory function of the nAChRs in human DCs, it has been shown that stimulation of the nAChRs reduces phagocytosis and endocytosis activities in human DC and decreases the levels of inflammatory cytokines production (IL-1 $\beta$, TNF- $\alpha$, and IL-12) triggered by LPS, which are crucial for the recruitment of $\mathrm{T}$ cells in response to inflammatory stimulation $[49,65]$. Additionally, some authors have suggested that the impairment of DCs function by nicotine may also be related to the increased occurrence of infections in smokers [60].

Interestingly, other studies have shown that nicotine, acting on resting human DCs, stimulates not only the expression of costimulatory molecules but also the production of IL12 and their ability to stimulate T-cell proliferation [43, 66, 67]. These results suggest that nicotinic stimulation might be able to exert different effects on DCs depending on their maturation status.

Similarly, Salamone et al. [40] have analyzed the ability of ACh to modulate the functional profile of human monocytederived DCs and found induced opposite effects on resting 


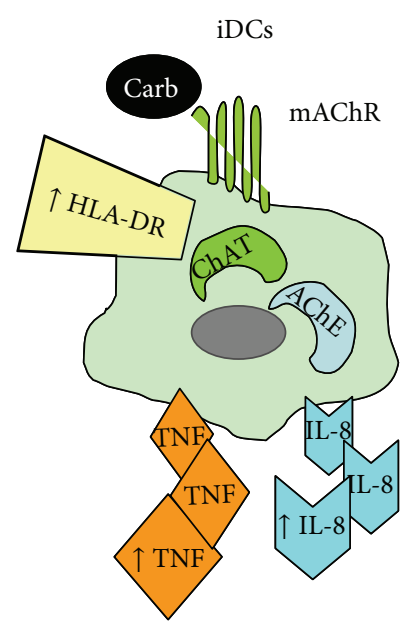

$\uparrow$ MMLR

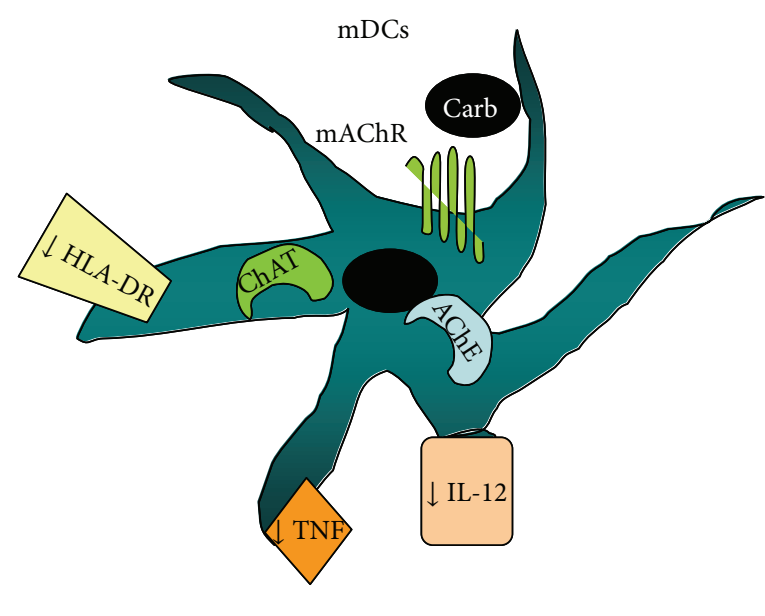

$\downarrow$ MMLR

FIGURE 3: Cholinergic actions on human dendritic cells (DCs). DCs express all the components of the nonneuronal cholinergic system: muscarinic acetylcholine receptors (mAChR), acetylcholine transferase (AChT), and acetylcholinesterase (AChE). The activation of mAChR with carbachol (Carb) in immature DCs (iDCs) upregulates deexpression of HLA-DR and the liberation of tumor necrosis factor (TNF) and interleukin-8 (IL-8) and stimulates demix lymphocyte reaction (MLR), while the activation of mAChR with Carb in mature DCs (mDCs) downregulates HLA-DR, TNF, and IL-12 and reduces MLR.

and LPS-triggered DCs indicating that the ability of the cholinergic system to modulate the functional profile of DCs is strongly dependent on their activation status. Besides, muscarinic stimulation increases the expression of HLADR and CD86 and the production of TNF- $\alpha$ and IL- 8 in immature DCs. The increment in HLA-DR expression by cholinergic activation is dependent on TNF- $\alpha$ production in an autocrine and/or paracrine manner. On the other hand, the addition of the muscarinic agonist carbachol to LPSstimulated DCs reduced the expression of HLA-DR and the production of TNF- $\alpha$ and IL-12 (Figure 3).

Interestingly, Liu et al. [44] have investigated the role of the mAChRs in nasal mucosal immune cells of patients with polyposis, which is associated with inflammatory disorders in the lower airways. They found that microbial products upregulate the expression of $\mathrm{M}_{3}$ receptor in nasal mucosal immune cells and as a consequence the cholinergic stimulation of DCs improves the inflammatory activity of these cells by increasing the production of OX40L. In addition, DCs modulate the production of TNF- $\alpha$ and IL- 4 in nasal mucosa by $\mathrm{CD} 4^{+} \mathrm{T}$ cells that may further contribute to the pathogenesis of polyposis.

\section{Functional Significance of Tumor-DCs Interactions}

Activation and maturation of DCs depend on the local microenvironment and can be blocked or polarized by specific factors or their combinations resulting in the formation of DCs subsets with tolerogenic and immunosuppressive activities $[68,69]$. The lineage relationship between these different subsets, their responsiveness to different pathogens, and the mechanisms by which they influence the immune response are areas of intense investigation and have been reviewed extensively [70, 71]. The tumor microenvironment is capable of inactivating various components of the immune system responsible for tumor clearance. In particular, the effect of the tumor microenvironment on DCs does not only render these immune cells unable to induce specific immune responses but also turns them into promoters of tumor growth.

7.1. DCs as Inducers of Tumor Immunity. According to the cancer immunosurveillance and immunoediting paradigm the immune system has the ability to detect and remove emerging malignant cells preventing their uncontrolled proliferation [72-75]. At the beginning of every cellular immune reaction against cancer, tumor antigens have to be presented to $\mathrm{T}$ cells in order to activate them and drive them into clonal expansion. This task is done by antigen presenting cells, the most potent of which are the DCs. Tumor-specific T-cell activation begins in the primary tumor when DCs encounter antigens in the form of apoptotic or necrotic tumor cells. Then, DCs engulf dying tumor cells and process their antigens into peptides that are presented in the context of MHC class I and class II molecules [76, 77]. In addition, T-cell activation requires engagement of costimulatory receptors on the T-cell, adequate types and concentrations of Tcell-activating cytokines and T-cell-attracting chemokines, and maintenance of the activation signal over a sufficient period of time. DCs can accurately control the outcome of immune activation by means of differential surface receptor expression, and $\mathrm{T}$ cells in turn signal back to modulate the function of DCs. Apart from generating an antitumor immune response, DCs also play an active role in the eradication of tumors themselves, since DCs have been shown to kill tumor cells via expression of death receptor ligands [78], and DCs activated by pro-inflammatory cytokines or LPS 
can directly inhibit the growth of tumor cell lines [79]. Thus, DC has the potential ability of developing tumorspecific immune response. However, this does not occur in most types of cancer or in animal models of spontaneously arising tumors. Instead of being eliminated by the immune response, tumors progress, metastasize, and, ultimately, result in death of the host. Much clear evidence has demonstrated deficient functional activity of DCs in cancer [77-80]. The main conclusion from these studies was that DCs in tumorbearing hosts could not adequately stimulate an immune response, and this could contribute to tumor evasion of immune recognition. Now, it is increasingly clear that the DCs defects in cancer are systemic and are not localized to tumor tissues.

7.2. DCs Infiltrating Breast Tumors. Innate immune cells (DCs, natural killer cells, granulocytes, myeloid derived suppressor cells, macrophages, and monocytes) are present in the normal mammary gland and play an important role in the function of the tissue actively participating in mammary gland development and remodelling [80-82]. They are present in even higher numbers in neoplastic tissues, such as breast tumors. This increased infiltration of innate immune cells in the tumor tissue might be seen as an attempt of the body to combat the disease. However, high infiltration correlates with poor prognosis for patients [83]. Thus, in line with these observations innate immune cells in vivo primarily exert activities that support tumor growth, for example, by stimulating angiogenesis [84]. In contrast, in vitro, innate immune cells possess effective antitumor activities, such as direct killing of cancer cells [85].

Observations from many clinical studies have noted infiltration of tumors with DCs [86]. The clinical significance of tumor-infiltrating DCs (TIDCs) has been reported in a large variety of human malignancies. In general, the presence of DCs in tumors has been associated with better prognosis, reduced tumor recurrence, and fewer metastases [87]. The S100 protein was the first marker introduced to identify DCs. TIDCs are heterogeneous in regard to maturation, differentiation, and state of activation and are controlled and regulated by a variety of microenvironmental signals, including cytokines and other surface molecules expressed on neighbouring cells [87]. The conceptual progress in the field of DCs physiology and the availability of novel markers differentiating DC subsets has allowed us to reevaluate DCs infiltration in breast carcinoma tissue. The use of specific markers has made it possible to identify the maturation state of TIDCs. Bell et al. have demonstrated the unique compartmentalization of immature and mature DCs infiltrating the breast carcinoma tissue [77]. These authors found that immature $\mathrm{CDla}^{+} \mathrm{DCs}$, mostly of the Langerhans cell type $\left(\right.$ Langerin $^{+}$), are retained in more than $90 \%$ of breast cancers within the tumor bed whereas mature DCs, $\mathrm{CD} 83^{+}$DC$\mathrm{Lamp}^{+}$, recorded in $60 \%$ of the examined samples, are confined to peritumoral areas. The high numbers of immature DCs found in the tumor may be best explained by high levels of macrophage inflammatory protein $3 \alpha$ (MIP-3 $3 \alpha$ /CCL20) expressed by virtually all tumor cells. In some cases, T cells cluster around mature DCs, resembling the DC and T-cell clusters of secondary lymphoid organs characteristic of ongoing immune reactions [87]. In a complementary study, Iwamoto et al. [88] have established the prognostic significance of tumor infiltration by immature and mature DCs by revealing that the presence of $\mathrm{CD} 83^{+}$TIDCs was inversely correlated with lymph node metastasis. These results were confirmed by other studies in which higher numbers of $\mathrm{CD}^{+} 3^{+} \mathrm{DCs}$ were found in tumor-free sentinel lymph node (SLNs) than in tumor-containing SLNs. In addition, tumor-free SLNs contained significantly higher numbers of IL-10-expressing cells. Both of these observations support the hypothesis that a tumor-free SLN is immunologically competent and a site of tumor-specific T-cell activation [89]. The mechanisms by which tumor immunity is affected within the SLN are not fully understood. However, it is well known that tumor cells produce various immunosuppressive factors, including TGF$\alpha$, IL-10, and PGE2, and vascular endothelial growth factor (VEGF) [90-92].

Studies using tissues from human breast cancer patients have documented infiltration of plasmacytoid DCs (pDCs) at the periphery of the tumor and at sites of metastasis $[93,94]$. pDCs are well known for their role in antiviral immunity as they massively produce type I interferons $(\operatorname{IFN} \alpha / \beta / \omega)$ in response to viral nucleic acids recognized by TLR7 and TLR9. They are also involved in the pathogenesis of autoimmune/inflammatory disorders. In addition to their innate immunostimulatory functions, $\mathrm{pDCs}$ exhibit adaptive tolerogenic properties by favouring the differentiation and expansion of immunosuppressive $\mathrm{FOXP}^{+}$regulatory $\mathrm{T}$ cells (Treg) [95]. The accumulation of pDCs within breast carcinoma lesions is associated with a poor clinical outcome. It was demonstrated that the deleterious impact of tumorassociated pDCs is due to their impaired capacity to produce type I interferon, which in turn potentiates their ability to sustain the proliferation of immunosuppressive Treg cells [96]. Elevated levels of pDCs have been observed as breast cancer disseminates to the bone suggesting that $\mathrm{pDCs}$ may play a key role in the establishment of breast cancer osteolytic bone metastases [97].

7.3. Circulating DCs in Breast Cancer Patients. Substantial evidence exists showing impairment of the systemic immune response during breast cancer progression. Several groups have described differences in differentiation of circulating monocytes into DCs which persisted in cancer patients as compared with healthy donors $[98,99]$. In patients with cancer, it has been shown that rapidly growing tumors contain small numbers of DCs and that those cells usually have the phenotype of immature DCs (iDCs) [100]. iDCs cannot induce antitumor immune responses but instead they are able to induce T-cell tolerance or anergy. Using the classic procedure of blood monocyte-derived DCs culture (in the presence of IL-4 and GM-CSF), the ex vivo yield of DCs was found to be significantly reduced in patients with cancer, particularly in those with breast cancer [101]. The phenotype of monocyte-derived DCs in patients with breast cancer was found to express low levels of MHC class II as compared with healthy patients. Moreover, whatever combination of maturating agents was used, significantly lower expressions 
of mature DC markers (CD80 and CD86) were observed in patients with breast cancer [98], whereas DCs isolated from breast cancer patients demonstrate impaired phagocytosis and a significantly reduced ability to stimulate allogeneic and antigen-specific T-cell responses [100]. Interestingly, pDC numbers are not affected. Several clinical studies have shown that surgical removal of tumors can increase the number of DCs in the peripheral blood of patients with cancer [102].

Tumor infiltrating and circulating blood DCs from cancer patients are compromised in their functional activity. Even though it is still under debate which factors are involved in the inhibitory activity of tumor cells, ex vivo culture seems to be able to circumvent the suppressive activity of the tumor milieu.

7.4. The Breast Cancer Immune Microenvironment. Development of cancer not only is determined by the tumor cells themselves but also depends on the tumor environment [103]. The tumor stroma consists of fibroblasts, endothelial cells, and extracellular matrix components and a considerable fraction of the inflammatory infiltrate is located within this tumor stroma. Besides the tumor cells, tumor stroma produces a variety of cofactors including cytokines, chemokines, growth factors, hormones, prostaglandins, lactate, and gangliosides. The interplay between all of these factors and cell populations defines the tumor environment $[104,105]$.

Breast tumors generate a milieu in which innate immune cells are skewed towards a type II polarization and are thus pushed towards roles as "villains" [105]. Anti-inflammatory cytokines, such as IL-10 and TGF- $\beta$, are the main contributors of this milieu. These factors are produced by tumor and stromal cells, and they act directly on immune cells by impairing their ability to secrete pro-inflammatory factors $[106,107]$. These anti-inflammatory signals may also be secreted by regulatory $\mathrm{T}$ cells, which are found in elevated numbers in human breast tumors [108].

7.5. Tumor-Derived Factors Involved in Defective DCs Differentiation and Activity. As it was mentioned above, DCs defect in cancer is systemic and this indicates that it is mediated by soluble factors produced by tumor cells. This concept is directly confirmed by the observation that normal DCs differentiation and activity are restored after surgical removal of tumors. Moreover, when DCs precursors isolated from tumor-bearing hosts are cultured in the absence of tumorcell-conditioned medium, the differentiation of DCs is normal [100]. The defects of DCs differentiation and activity in cancer are due to the combination of many different factors which will be briefly summarized herein.

7.5.1. Vascular Endothelial Growth Factor (VEGF). This was the first tumor-derived factor shown to inhibit DCs differentiation. VEGF has an important role in the formation of blood vessels and in haematopoiesis during embryogenesis. VEGF plays dual roles in the tumor microenvironment by inducing angiogenesis and inhibiting DCs function [109]. In recent years, large clinical data have supported the fact that the expression of VEGF negatively correlates with DCs numbers in the tumor tissue and peripheral blood of patients with cancer [110].

7.5.2. Interleukin-10 (IL-10). Different tumor, stromal cells, and tumor-infiltrating lymphocytes produce and release IL10 [111]. Anti-inflammatory cytokines, such as IL-10, act directly on immune cells by impairing their ability to secrete pro-inflammatory factors. IL-10 promotes the differentiation of iDCs into tolerogenic DCs by decreasing their expression of co-stimulatory molecules [112]. IL-10 has also been shown to block the differentiation of monocytes into DCs, but it promotes their maturation into macrophages [113].

7.5.3. Other Tumor Metabolites. Arachidonic acid metabolites, including prostaglandins and thromboxanes, are synthesized by cyclooxygenase- 1 and 2 (COX-1/2). In many cancers, such as melanoma, colon, breast, lung, and ovarian carcinoma the expression of COX-2 is altered [114, 115]. Besides the direct effect on tumor growth, apoptosis, cell to cell interaction, and angiogenesis, prostanoids seem to suppress host immunity against tumors [116] with particular effects on DCs activity [117]. Prostaglandin $\mathrm{E}_{2}\left(\mathrm{PGE}_{2}\right)$ was also described as an important factor for the generation of potent T-cell stimulatory DCs. When DCs are cultured simultaneously with a cocktail of pro-inflammatory cytokines including IL$6, \mathrm{IL}-1 \beta$, and TNF- $\alpha$ in the presence of $\mathrm{PGE}_{2}$ the mature DCs obtained present potent $\mathrm{T}$-cell stimulatory capacity [118]. Furthermore, the migratory capacity of monocyte-derived DCs seems to depend on the presence of $\mathrm{PGE}_{2}$ and increases the expression of CCR7, the CCL19/CCL21 receptor [119]. On the other hand, $\mathrm{PGE}_{2}$ upregulates indoleamine 2,3-dioxygenase (IDO) thereby inhibiting $\mathrm{T}$ cell proliferation due to IDOinduced tryptophan depletion [120] and thus inducing DCsmediated T-cell tolerance in the tumor microenvironment.

\section{Concluding Remarks}

Many aspects of breast cancer promotion and progression are still not completely solved. The activation of $\mathrm{mAChRs}$ in breast tumors promotes malignant progression and worsens the condition of tumor bearers. In particular, the activation of cholinergic receptors in immature DCs could favor tumor antigen presentation through HLA-DR expression and on the other hand could promote a pro-inflammatory status facilitating antitumor responses that control tumor growth. Altogether, stimulation of mAChRs in DCs should be considered as an adjuvant target in cancer therapeutics to break DCs tolerance against tumors.

\section{Conflict of Interests}

The authors declare that there is no conflict of interests. M. Vulcano, M. G. Lombardi, and M. E. Sales are members of the Researcher Career of CONICET.

\section{References}

[1] Y. Abreu-Villaça, C. C. Filgueiras, and A. C. Manhães, "Developmental aspects of the cholinergic system," Behavioural Brain Research, vol. 221, no. 1, pp. 282-289, 2011. 
[2] I. Wessler, C. J. Kirkpatrick, and K. Racké, "Non-neuronal acetylcholine, a locally acting molecule, widely distributed in biological systems: expression and function in humans," Pharmacology and Therapeutics, vol. 77, no. 1, pp. 59-79, 1998.

[3] S. A. Grando, "Biological functions of keratinocyte cholinergic receptors," Journal of Investigative Dermatology Symposium Proceedings, vol. 2, no. 1, pp. 41-48, 1997.

[4] I. Wessler, C. J. Kirkpatrick, and K. Racké, "The cholinergic "pitfall": acetylcholine, a universal cell molecule in biological systems, including humans," Clinical and Experimental Pharmacology and Physiology, vol. 26, no. 3, pp. 198-205, 1999.

[5] I. Wessler, E. Roth, C. Deutsch et al., "Release of non-neuronal acetylcholine from the isolated human placenta is mediated by organic cation transporters," British Journal of Pharmacology, vol. 134, no. 5, pp. 951-956, 2001.

[6] I. Wessler, E. Roth, S. Schwarze et al., "Release of non-neuronal acetylcholine from the human placenta: difference to neuronal acetylcholine," Naunyn-Schmiedeberg's Archives of Pharmacology, vol. 364, no. 3, pp. 205-212, 2001.

[7] M. P. Caulfield and N. J. M. Birdsall, "International union of pharmacology. XVII. Classification of muscarinic acetylcholine receptors," Pharmacological Reviews, vol. 50, no. 2, pp. 279-290, 1998.

[8] W. M. Oldham and H. E. Hamm, "Structural basis of function in heterotrimeric G proteins," Quarterly Reviews of Biophysics, vol. 39, no. 2, pp. 117-166, 2006.

[9] M. P. Caulfield, "Muscarinic receptors: characterization, coupling and function," Pharmacology and Therapeutics, vol. 58, no. 3, pp. 319-379, 1993.

[10] C. C. Felder, "Muscarinic acetylcholine receptors: signal transduction through multiple effectors," The FASEB Journal, vol. 9, no. 8, pp. 619-625, 1995 .

[11] A. A. Lanzafame, A. Christopoulos, and F. Mitchelson, "Cellular signaling mechanisms for muscarinic acetylcholine receptors," Receptors and Channels, vol. 9, no. 4, pp. 241-260, 2003.

[12] R. M. Eglen, "Muscarinic receptor subtypes in neuronal and non-neuronal cholinergic function," Autonomic and Autacoid Pharmacology, vol. 26, no. 3, pp. 219-233, 2006.

[13] N. Wang, A. Orr-Urtreger, and A. D. Korczyn, “The role of neuronal nicotinic acetylcholine receptor subunits in autonomic ganglia: lessons from knockout mice," Progress in Neurobiology, vol. 68, no. 5, pp. 341-360, 2002.

[14] S. A. Grando, "Basic and clinical aspects of non-neuronal acetylcholine: biological and clinical significance of non-canonical ligands of epithelial nicotinic acetylcholine receptors," Journal of Pharmacological Sciences, vol. 106, no. 2, pp. 174-179, 2008.

[15] N. Struckmann, S. Schwering, S. Wiegand et al., "Role of muscarinic receptor subtypes in the constriction of peripheral airways: studies on receptor-deficient mice," Molecular Pharmacology, vol. 64, no. 6, pp. 1444-1451, 2003.

[16] P. Song, H. S. Sekhon, B. Proskocil, J. K. Blusztajn, G. P. Mark, and E. R. Spindel, "Synthesis of acetylcholine by lung cancer," Life Sciences, vol. 72, no. 18-19, pp. 2159-2168, 2003.

[17] J.-I. Ukegawa, Y. Takeuchi, S. Kusayanagi, and K. Mitamura, "Growth-promoting effect of muscarinic acetylcholine receptors in colon cancer cells," Journal of Cancer Research and Clinical Oncology, vol. 129, no. 5, pp. 272-278, 2003.

[18] H. Kurzen, C. Henrich, D. Booken et al., "Functional characterization of the epidermal cholinergic system in vitro," Journal of Investigative Dermatology, vol. 126, no. 11, pp. 2458-2472, 2006.
[19] J. W. Bowers, S. M. Schlauder, K. B. Calder, and M. B. Morgan, "Acetylcholine receptor expression in merkel cell carcinoma," American Journal of Dermatopathology, vol. 30, no. 4, pp. 340343, 2008.

[20] J. N. Larocca and G. Almazan, "Acetylcholine agonists stimulate mitogen-activated protein kinase in oligodendrocyte progenitors by muscarinic receptors," Journal of Neuroscience Reseaarch, vol. 50, no. 5, pp. 743-754, 1997.

[21] F. De Angelis, A. Bernardo, V. Magnaghi, L. Minghetti, and A. M. Tata, "Muscarinic receptor subtypes as potential targets to modulate oligodendrocyte progenitor survival, proliferation, and differentiation," Developmental Neurobiology, vol. 72, no. 5, pp. 713-728, 2012.

[22] D. G. Lambert, R. J. H. Wojcikiewicz, S. T. Safrany, E. M. Whitham, and S. R. Nahorski, "Muscarinic receptors, phosphoinositide metabolism and intracellular calcium in neuronal cells," Progress in Neuro-Psychopharmacology and Biological Psychiatry, vol. 16, no. 3, pp. 253-270, 1992.

[23] A. J. Español and M. E. Sales, "Different muscarinc receptors are involved in the proliferation of murine mammary adenocarcinoma cell lines," International Journal of Molecular Medicine, vol. 13, no. 2, pp. 311-317, 2004.

[24] M. P. Negroni, G. L. Fiszman, M. E. Azar et al., "Immunoglobulin $\mathrm{G}$ from breast cancer patients in stage i stimulates muscarinic acetylcholine receptors in MCF7 cells and induces proliferation. Participation of nitric oxide synthase-derived nitric oxide," Journal of Clinical Immunology, vol. 30, no. 3, pp. 474-484, 2010.

[25] G. L. Fiszman and M. E. Sales, "Antibodies against muscarinic receptors in breast cancer: agonizing tumor growth," Current Immunology Reviews, vol. 4, no. 3, pp. 176-182, 2008.

[26] A. Español, A. M. Eiján, E. Mazzoni et al., "Nitric oxide synthase, arginase and cyclooxygenase are involved in muscarinic receptor activation in different murine mammary adenocarcinoma cell lines," International Journal of Molecular Medicine, vol. 9, no. 6, pp. 651-657, 2002.

[27] L. Rimmaudo, E. de la Torre, and M. E. Sales, "Muscarinic receptors are involved in LMM3 tumor cells proliferation and angiogenesis," Biochemical and Biophysical Research Communications, vol. 334, no. 4, pp. 1359-1365, 2005.

[28] A. J. Español, E. de la Torre, G. L. Fiszman, and M. E. Sales, "Role of non-neuronal cholinergic system in breast cancer progression," Life Sciences, vol. 80, no. 24-25, pp. 2281-2285, 2007.

[29] G. L. Fiszman, M. C. Middonno, E. de la Torre, M. Farina, A. J. Español, and M. E. Sales, "Activation of muscarinic cholinergic receptors induces MCF-7 cells proliferation and angiogenesis by stimulating nitric oxide synthase activity," Cancer Biology and Therapy, vol. 6, no. 7, pp. 1106-1113, 2007.

[30] M. G. Lombardi, M. P. Negroni, L. T. Pelegrina et al., "Autoantibodies against muscarinic receptors in breast cancer: their role in tumor angiogenesis," PLoS ONE, vol. 8, no. 2, Article ID e57572, 2013

[31] L. T. Pelegrina, M. G. Lombardi, G. L. Fiszman, M. E. Azar, C. C. Morgado, and M. E. Sales, "Immunoglobulin G from breast cancer patients regulates MCF-7 cells migration and MMP9 activity by stimulating muscarinic acetylcholine receptors," Journal of Clinical Immunology, vol. 33, no. 2, pp. 427-435, 2013.

[32] K. Kawashima, K. Kajiyama, K. Fujimoto, H. Oohata, and T. Suzuki, "Presence of acetylcholine in blood and its localization in circulating mononuclear leukocytes of humans," Biogenic Amines, vol. 9, no. 4, pp. 251-258, 1993. 
[33] T. Fujii, Y. Takada-Takatori, and K. Kawashima, "Regulatory mechanisms of acetylcholine synthesis and release by T cells," Life Science, vol. 91, no. 21-22, pp. 981-985, 2012.

[34] I. Rinner, K. Kawashima, and K. Schauenstein, "Rat lymphocytes produce and secrete acetylcholine in dependence of differentiation and activation," Journal of Neuroimmunology, vol. 81, no. 1-2, pp. 31-37, 1998.

[35] T. Fujii, Y. Watanabe, K. Fujimoto, and K. Kawashima, "Expression of acetylcholine in lymphocytes and modulation of an independent lymphocytic cholinergic activity by immunological stimulation," Biogenic Amines, vol. 17, no. 4-6, pp. 373-386, 2003.

[36] I. Wessler and C. J. Kirkpatrick, "Acetylcholine beyond neurons: the non-neuronal cholinergic system in humans," British Journal of Pharmacology, vol. 154, no. 8, pp. 1558-1571, 2008.

[37] K. Kawashima and T. Fujii, "Extraneuronal cholinergic system in lymphocytes," Pharmacology and Therapeutics, vol. 86, no. 1 , pp. 29-48, 2000.

[38] K. Kawashima and T. Fujii, "Expression of non-neuronal acetylcholine in lymphocytes and its contribution to the regulation of immune function," Frontiers in Bioscience, vol. 9, pp. 2063-2085, 2004.

[39] E. Hagforsen, A. Einarsson, F. Aronsson, K. Nordlind, and G. Michaëlsson, "The distribution of choline acetyltransferaseand acetylcholinesterase-like immunoreactivity in the palmar skin of patients with palmoplantar pustulosis," British Journal of Dermatology, vol. 142, no. 2, pp. 234-242, 2000.

[40] G. Salamone, G. Lombardi, S. Gori et al., "Cholinergic modulation of dendritic cell function," Journal of Neuroimmunology, vol. 236, no. 1-2, pp. 47-56, 2011.

[41] A. Koarai, S. L. Traves, P. S. Fenwick et al., "Expression of muscarinic receptors by human macrophages," European Respiratory Journal, vol. 39, no. 3, pp. 698-704, 2012.

[42] J. Qian, V. Galitovskiy, A. I. Chernyavsky, S. Marchenko, and S. A. Grando, "Plasticity of the murine spleen T-cell cholinergic receptors and their role in in vitro differentiation of nave CD4 T cells toward the Th1, Th2 and Th17 lineages," Genes and Immunity, vol. 12, no. 3, pp. 222-230, 2011.

[43] A. Aicher, C. Heeschen, M. Mohaupt, J. P. Cooke, A. M. Zeiher, and S. Dimmeler, "Nicotine strongly activates dendritic cellmediated adaptive immunity: potential role for progression of atherosclerotic lesions," Circulation, vol. 107, no. 4, pp. 604-611, 2003.

[44] T. Liu, C. Xie, X. Chen et al., "Role of muscarinic receptor activation in regulating immune cell activity in nasal mucosa," Allergy, vol. 65, no. 8, pp. 969-977, 2010.

[45] J. C. Zimring, L. M. Kapp, M. Yamada, J. Wess, and J. A. Kapp, "Regulation of CD8+ cytolytic T lymphocyte differentiation by a cholinergic pathway," Journal of Neuroimmunology, vol. 164, no. 1-2, pp. 66-75, 2005.

[46] K. Kawashima and T. Fujii, "The lymphocytic cholinergic system and its contribution to the regulation of immune activity," Life Sciences, vol. 74, no. 6, pp. 675-696, 2003.

[47] E. Sato, S. Koyama, Y. Okubo, K. Kubo, and M. Sekiguchi, "Acetylcholine stimulates alveolar macrophages to release inflammatory cell chemotactic activity," American Journal of Physiology_Lung Cellular and Molecular Physiology, vol. 274, no. 6, pp. L970-L979, 1998.

[48] F. Bühling, N. Lieder, U. C. Kühlmann, N. Waldburg, and T. Welte, "Tiotropium suppresses acetylcholine-induced release of chemotactic mediators in vitro," Respiratory Medicine, vol. 101, no. 11, pp. 2386-2394, 2007.
[49] E. P. van der Zanden, S. A. Snoek, S. E. Heinsbroek et al., "Vagus nerve activity augments intestinal macrophage phagocytosis via nicotinic acetylcholine receptor alpha4beta2," Gastroenterology, vol. 137, no. 3, pp. 1029.e4-1039.e4, 2009.

[50] P. F. Zabrodskii, V. G. Lim, M. S. Shekhter, and A. V. Kuzmin, "Role of nicotinic and muscarinic cholinoreceptors in the realization of the cholinergic anti-inflammatory pathway during the early phase of sepsis," Bulletin of Experimental Biology and Medicine, vol. 153, no. 5, pp. 700-703, 2012.

[51] L. V. Borovikova, S. Ivanova, M. Zhang et al., "Vagus nerve stimulation attenuates the systemic inflammatory response to endotoxin," Nature, vol. 405, no. 6785, pp. 458-462, 2000.

[52] E. Nizri, Y. Hamra-Amitay, C. Sicsic, I. Lavon, and T. Brenner, "Anti-inflammatory properties of cholinergic up-regulation: a new role for acetylcholinesterase inhibitors," Neuropharmacology, vol. 50, no. 5, pp. 540-547, 2006.

[53] H. Wang, M. Yu, M. Ochani et al., "Nicotinic acetylcholine receptor $\alpha 7$ subunit is an essential regulator of inflammation," Nature, vol. 421, no. 6921, pp. 384-388, 2003.

[54] M. A. van Maanen, M. C. Lebre, T. van der Poll et al., "Stimulation of nicotinic acetylcholine receptors attenuates collageninduced arthritis in mice," Arthritis and Rheumatism, vol. 60, no. 1, pp. 114-122, 2009.

[55] K. Matsunaga, T. W. Klein, H. Friedman, and Y. Yamamoto, "Involvement of nicotinic acetylcholine receptors in suppression of antimicrobial activity and cytokine responses of alveolar macrophages to Legionella pneumophila infection by nicotine," Journal of Immunology, vol. 167, no. 11, pp. 6518-6524, 2001.

[56] S. Razani-Boroujerdi, R. T. Boyd, M. I. Dávila-García et al., "T cells express $\alpha 7$-nicotinic acetylcholine receptor subunits that require a functional TCR and leukocyte-specific protein tyrosine kinase for nicotine-induced $\mathrm{Ca}^{2+}$ response," Journal of Immunology, vol. 179, no. 5, pp. 2889-2898, 2007.

[57] T. Fujii, Y. Watanabe, T. Inoue, and K. Kawashima, "Upregulation of mRNA encoding the M5 muscarinic acetylcholine receptor in human T- and B-lymphocytes during immunological responses," Neurochemical Research, vol. 28, no. 3-4, pp. 423429, 2003.

[58] Y. X. Fujii, A. Tashiro, K. Arimoto et al., "Diminished antigen-specific IgG1 and interleukin-6 production and acetylcholinesterase expression in combined M1 and M5 muscarinic acetylcholine receptor knockout mice," Journal of Neuroimmunology, vol. 188, no. 1-2, pp. 80-85, 2007.

[59] I. Wessler, F. Bittinger, W. Kamin et al., "Dysfunction of the nonneuronal cholinergic system in the airways and blood cells of patients with cystic fibrosis," Life Sciences, vol. 80, no. 24-25, pp. 2253-2258, 2007.

[60] I. Wessler, S. Neumann, M. Razen, F. Zepp, and C. J. Kirkpatrick, "Blockade of nicotinic and muscarinic receptors facilitates spontaneous migration of human peripheral granulocytes: failure in cystic fibrosis," Life Sciences, vol. 91, no. 21-22, pp. 11191121, 2012.

[61] M. N. Meriggioli and D. B. Sanders, "Autoimmune myasthenia gravis: emerging clinical and biological heterogeneity," The Lancet Neurology, vol. 8, no. 5, pp. 475-490, 2009.

[62] A. Vincent, "Unravelling the pathogenesis of myasthenia gravis," Nature Reviews Immunology, vol. 2, no. 10, pp. 797-804, 2002.

[63] R. M. Steinman, "The dendritic cell system and its role in immunogenicity," Annual Review of Immunology, vol. 9, pp. 271296, 1991. 
[64] M. R. Shurin, "Dendritic cells presenting tumor antigen," Cancer Immunology Immunotherapy, vol. 43, no. 3, pp. 158-164, 1996.

[65] M. Nouri-Shirazi and E. Guinet, "Evidence for the immunosuppressive role of nicotine on human dendritic cell functions," Immunology, vol. 109, no. 3, pp. 365-373, 2003.

[66] G. G. Feng, F. Wan da, and R. G. Jian, “Ex vivo nicotine stimulation augments the efficacy of therapeutic bone marrowderived dendritic cell vaccination," Clinical Cancer Research, vol. 13, no. 12, pp. 3706-3712, 2007.

[67] H. J. Jin, H. T. Li, H. X. Sui et al., "Nicotine stimulated bone marrow-derived dendritic cells could augment HBV specific CTL priming by activating PI3K-Akt pathway," Immunology Letters, vol. 146, no. 1-2, pp. 40-49, 2012.

[68] R. M. Steinman, D. Hawiger, and M. C. Nussenzweig, "Tolerogenic dendritic cells," Annual Review of Immunology, vol. 21, pp. 685-711, 2003.

[69] S. Manicassamy and B. Pulendran, "Dendritic cell control of tolerogenic responses," Immunological Reviews, vol. 241, no. 1, pp. 206-227, 2011.

[70] R. M. Steinman and H. Hemmi, "Dendritic cells: translating innate to adaptive immunity," Current Topics in Microbiology and Immunology, vol. 311, pp. 17-58, 2006.

[71] H. Ueno, E. Klechevsky, R. Morita et al., "Dendritic cell subsets in health and disease," Immunological Reviews, vol. 219, no. 1, pp. 118-142, 2007.

[72] G. P. Dunn, A. T. Bruce, H. Ikeda, L. J. Old, and R. D. Schreiber, "Cancer immunoediting: from immunosurveillance to tumor escape," Nature Immunology, vol. 3, no. 11, pp. 991-998, 2002.

[73] A. J. Coyle and J. Gutierrez-Ramos, "The expanding B7 superfamily: increasing complexity in costimulatory signals regulating T cell function," Nature Immunology, vol. 2, no. 3, pp. 203-209, 2001.

[74] J. D. Bui and R. D. Schreiber, "Cancer immunosurveillance, immunoediting and inflammation: independent or interdependent processes?" Current Opinion in Immunology, vol. 19, no. 2, pp. 203-208, 2007.

[75] M. J. Smyth, G. P. Dunn, and R. D. Schreiber, "Cancer immunosurveillance and immunoediting: the roles of immunity in suppressing tumor development and shaping tumor immunogenicity," Advances in Immunology, vol. 90, pp. 1-50, 2006.

[76] J. Banchereau and R. M. Steinman, "Dendritic cells and the control of immunity," Nature, vol. 392, no. 6673, pp. 245-252, 1998.

[77] D. Bell, P. Chomarat, D. Broyles et al., "In breast carcinoma tissue, immature dendritic cells reside within the tumor, whereas mature dendritic cells are located in peritumoral areas," Journal of Experimental Medicine, vol. 190, no. 10, pp. 1417-1426, 1999.

[78] N. A. Fanger, C. R. Maliszewski, K. Schooley, and T. S. Griffith, "Human dendritic cells mediate cellular apoptosis via tumor necrosis factor-related apoptosis-inducing ligand (TRAIL)," Journal of Experimental Medicine, vol. 190, no. 8, pp. 1155-1164, 1999.

[79] A. I. Chapoval, K. Tamada, and L. Chen, "In vitro growth inhibition of a broad spectrum of tumor cell lines by activated human dendritic cells," Blood, vol. 95, no. 7, pp. 2346-2351, 2000.

[80] V. Gouon-Evans, E. Y. Lin, and J. W. Pollard, "Requirement of macrophages and eosinophils and their cytokines/chemokines for mammary gland development," Breast Cancer Research, vol. 4, no. 4, pp. 155-164, 2002.
[81] K. Atabai, D. Sheppard, and Z. Werb, "Roles of the innate immune system in mammary gland remodeling during involution," Journal of Mammary Gland Biology and Neoplasia, vol. 12, no. 1, pp. 37-45, 2007.

[82] T. Kees and M. Egeblad, "Innate immune cells in breast cancerfrom villains to heroes?" Journal of Mammary Gland Biology and Neoplasia, vol. 16, no. 3, pp. 189-203, 2011.

[83] M. J. Campbell, N. Y. Tonlaar, E. R. Garwood et al., "Proliferating macrophages associated with high grade, hormone receptor negative breast cancer and poor clinical outcome," Breast Cancer Research and Treatment, vol. 128, no. 3, pp. 703-711, 2010.

[84] A. Mantovani and A. Sica, "Macrophages, innate immunity and cancer: balance, tolerance, and diversity," Current Opinion in Immunology, vol. 22, no. 2, pp. 231-237, 2010.

[85] I. J. Fidler and A. J. Schroit, "Recognition and destruction of neoplastic cells by activated macrophages: discrimination of altered self," Biochimica et Biophysica Acta, vol. 948, no. 2, pp. 151-173, 1988.

[86] O. Preynat-Seauve, P. Schuler, E. Contassot, F. Beermann, B. Huard, and L. E. French, "Tumor-infiltrating dendritic cells are potent antigen-presenting cells able to activate $\mathrm{T}$ cells and mediate tumor rejection," The Journal of Immunology, vol. 176, no. 1, pp. 61-67, 2006.

[87] Y. Becker, "Anticancer role of dendritic cells (DC) in human and experimental cancers-a review," Anticancer Research, vol. 12, no. 2, pp. 511-520, 1992.

[88] M. Iwamoto, H. Shinohara, A. Miyamoto et al., "Prognostic value of tumor-infiltrating dendritic cells expressing CD83 in human breast carcinomas," International Journal of Cancer, vol. 104, no. 1, pp. 92-97, 2003.

[89] N. J. Poindexter, A. Sahin, K. K. Hunt, and E. A. Grimm, "Analysis of dendritic cells in tumor-free and tumor-containing sentinel lymph nodes from patients with breast cancer," Breast Cancer Research, vol. 6, no. 4, pp. R408-R415, 2004.

[90] C. T. Conrad, N. R. Ernst, W. Dummer, E. B. Bröcker, and J. C. Becker, "Differential expression of transforming growth factor $\beta 1$ and interleukin 10 in progressing and regressing areas of primary melanoma," Journal of Experimental and Clinical Cancer Research, vol. 18, no. 2, pp. 225-232, 1999.

[91] K. D. Amoils and W. R. Bezwoda, "TGF- $\beta 1$ mRNA expression in clinical breast cancer and its relationship to ER mRNA expression," Breast Cancer Research and Treatment, vol. 42, no. 2, pp. 95-101, 1997.

[92] L. Yang and D. P. Carbone, "Tumor-host immune interactions and dendritic cell dysfunction," Advances in Cancer Research, vol. 92, pp. 13-27, 2004.

[93] S. Ferrari, F. Malugani, B. Rovati, C. Porta, A. Riccardi, and M. Danova, "Flow cytometric analysis of circulating dendritic cell subsets and intracellular cytokine production in advanced breast cancer patients," Oncology Reports, vol. 14, no. 1, pp. 113120, 2005.

[94] I. Treilleux, J. Blay, N. Bendriss-Vermare et al., "Dendritic cell infiltration and prognosis of early stage breast cancer," Clinical Cancer Research, vol. 10, no. 22, pp. 7466-7474, 2004.

[95] B. M. Matta, A. Castellaneta, and A. W. Thomson, "Tolerogenic plasmacytoid DC," European Journal of Immunology, vol. 40, no. 10, pp. 2667-2676, 2010.

[96] V. Sisirak, J. Faget, N. Vey et al., "Plasmacytoid dendritic cells deficient in IFN $\alpha$ production promote the amplification of FOXP3+ regulatory $\mathrm{T}$ cells and are associated with poor prognosis in breast cancer patients," Oncoimmunology, vol. 2, no. 1, Article ID e22338, 2013. 
[97] A. Sawant and S. Ponnazhagan, "Role of plasmacytoid dendritic cells in breast cancer bone dissemination," OncoImmunology, vol. 2, no. 2, Article ID e22983, 2013.

[98] A. Gervais, J. Levêque, F. Bouet-Toussaint et al., "Dendritic cells are defective in breast cancer patients: a potential role for polyamine in this immunodeficiency," Breast Cancer Research, vol. 7, no. 3, pp. R326-R335, 2005.

[99] S. Satthaporn, A. Robins, W. Vassanasiri et al., "Dendritic cells are dysfunctional in patients with operable breast cancer," Cancer Immunology, Immunotherapy, vol. 53, no. 6, pp. 510-518, 2004.

[100] D. I. Gabrilovich, J. Corak, I. F. Ciernik, D. Kavanaugh, and D. P. Carbone, "Decreased antigen presentation by dendritic cells in patients with breast cancer," Clinical Cancer Research, vol. 3, no. 3, pp. 483-490, 1997.

[101] B. Almand, J. R. Resser, B. Lindman et al., "Clinical significance of defective dendritic cell differentiation in cancer," Clinical Cancer Research, vol. 6, no. 5, pp. 1755-1766, 2000.

[102] D. Gabrilovich, "Mechanisms and functional significance of tumour-induced dendritic-cell defects," Nature Reviews Immunology, vol. 4, no. 12, pp. 941-952, 2004.

[103] D. Ribatti, G. Mangialardi, and A. Vacca, "Stephen Paget and the "seed and soil" theory of metastatic dissemination," Clinical and Experimental Medicine, vol. 6, no. 4, pp. 145-149, 2006.

[104] M. R. Shurin, G. V. Shurin, A. Lokshin et al., "Intratumoral cytokines/chemokines/growth factors and tumor infiltrating dendritic cells: friends or enemies?" Cancer and Metastasis Reviews, vol. 25, no. 3, pp. 333-356, 2006.

[105] S. Kusmartsev and D. I. Gabrilovich, "Effect of tumor-derived cytokines and growth factors on differentiation and immune suppressive features of myeloid cells in cancer," Cancer and Metastasis Reviews, vol. 25, no. 3, pp. 323-331, 2006.

[106] J. Li, H. Zhu, T. Chen, G. Dai, and L. Zou, "TGF- $\beta 1$ and BRCA2 expression are associated with clinical factors in breast cancer," Cell Biochemistry and Biophysics, vol. 60, no. 3, pp. 245-248, 2011.

[107] M. C. Heckel, A. Wolfson, C. A. Slachta et al., "Human breast tumor cells express IL-10 and IL-12p40 transcripts and proteins, but do not produce IL-12p70," Cellular Immunology, vol. 266, no. 2, pp. 143-153, 2011.

[108] U. K. Liyanage, T. T. Moore, H. Joo et al., "Prevalence of regulatory $\mathrm{T}$ cells is increased in peripheral blood and tumor microenvironment of patients with pancreas or breast adenocarcinoma," Journal of Immunology, vol. 169, no. 5, pp. 27562761, 2002.

[109] A. Lin, A. Schildknecht, L. T. Nguyen, and P. S. Ohashi, "Dendritic cells integrate signals from the tumor microenvironment to modulate immunity and tumor growth," Immunology Letters, vol. 127, no. 2, pp. 77-84, 2010.

[110] M. Toi, T. Matsumoto, and H. Bando, "Vascular endothelial growth factor: its prognostic, predictive, and therapeutic implications," The Lancet Oncology, vol. 2, no. 11, pp. 667-673, 2001.

[111] N. Seo, S. Hayakawa, M. Takigawa, and Y. Tokura, "Interleukin10 expressed at early tumour sites induces subsequent generation of CD4+ T-regulatory cells and systemic collapse of antitumour immunity," Immunology, vol. 103, no. 4, pp. 449457, 2001.

[112] K. Steinbrink, M. Wölfl, H. Jonuleit, J. Knop, and A. H. Enk, "Induction of tolerance by IL-10-treated dendritic cells," Journal of Immunology, vol. 159, no. 10, pp. 4772-4780, 1997.
[113] P. Allavena, L. Piemonti, D. Longoni et al., "IL-10 prevents the differentiation of monocytes to dendritic cells but promotes their maturation to macrophages," European Journal Immunology, vol. 28, pp. 359-363, 1998.

[114] S. Gately and W. W. Li, "Multiple roles of COX-2 in tumor angiogenesis: a target for antiangiogenic therapy," Seminars in Oncology, vol. 31, no. 7, pp. 2-11, 2004.

[115] C. Denkert, M. Köbel, S. Berger et al., "Expression of cyclooxygenase 2 in human malignant melanoma," Cancer Research, vol. 61, no. 1, pp. 303-308, 2001.

[116] S. Tsuji, M. Tsujii, S. Kawano, and M. Hori, "Cyclooxygenase-2 upregulation as a perigenetic change in carcinogenesis," Journal of Experimental and Clinical Cancer Research, vol. 20, no. 1, pp. 117-129, 2001.

[117] S. Sharma, M. Stolina, S. Yang et al., "Tumor cyclooxygenase 2-dependent suppression of dendritic cell function," Clinical Cancer Research, vol. 9, no. 3, pp. 961-968, 2003.

[118] H. Jonuleit, U. Kühn, G. Müller et al., "Pro-inflammatory cytokines and prostaglandins induce maturation of potent immunostimulatory dendritic cells under fetal calf serum-free conditions," European Journal of Immunology, vol. 27, no. 12, pp. 3135-3142, 1997.

[119] E. Scandella, Y. Men, S. Gillessen, R. Förster, and M. Groettrup, "Prostaglandin E2 is a key factor for CCR7 surface expression and migration of monocyte-derived dendritic cells," Blood, vol. 100, no. 4, pp. 1354-1361, 2002.

[120] D. H. Munn, M. D. Sharma, J. R. Lee et al., "Potential regulatory function of human dendritic cells expressing indoleamine 2,3dioxygenase," Science, vol. 297, no. 5588, pp. 1867-1870, 2002. 

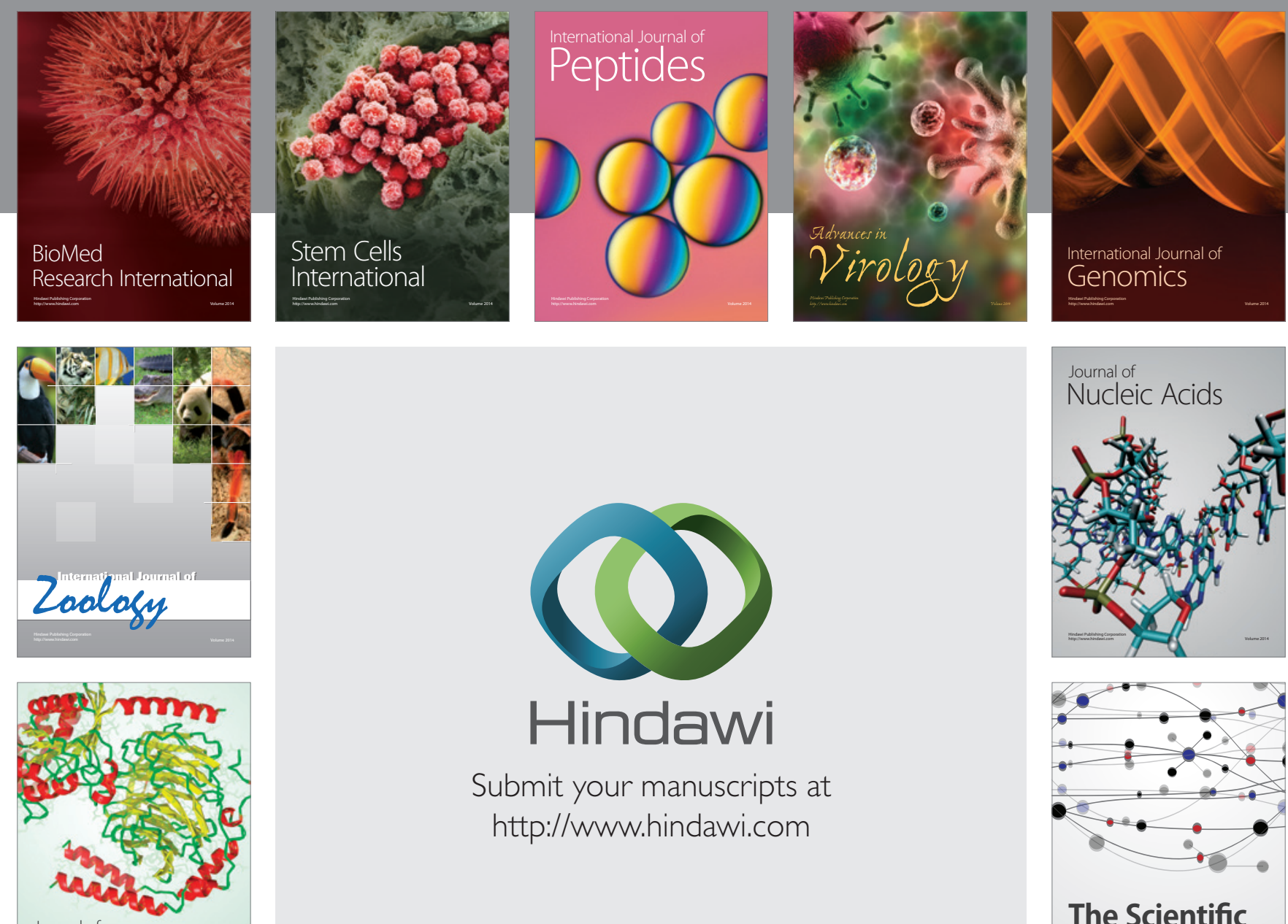

Submit your manuscripts at

http://www.hindawi.com

Journal of
Signal Transduction
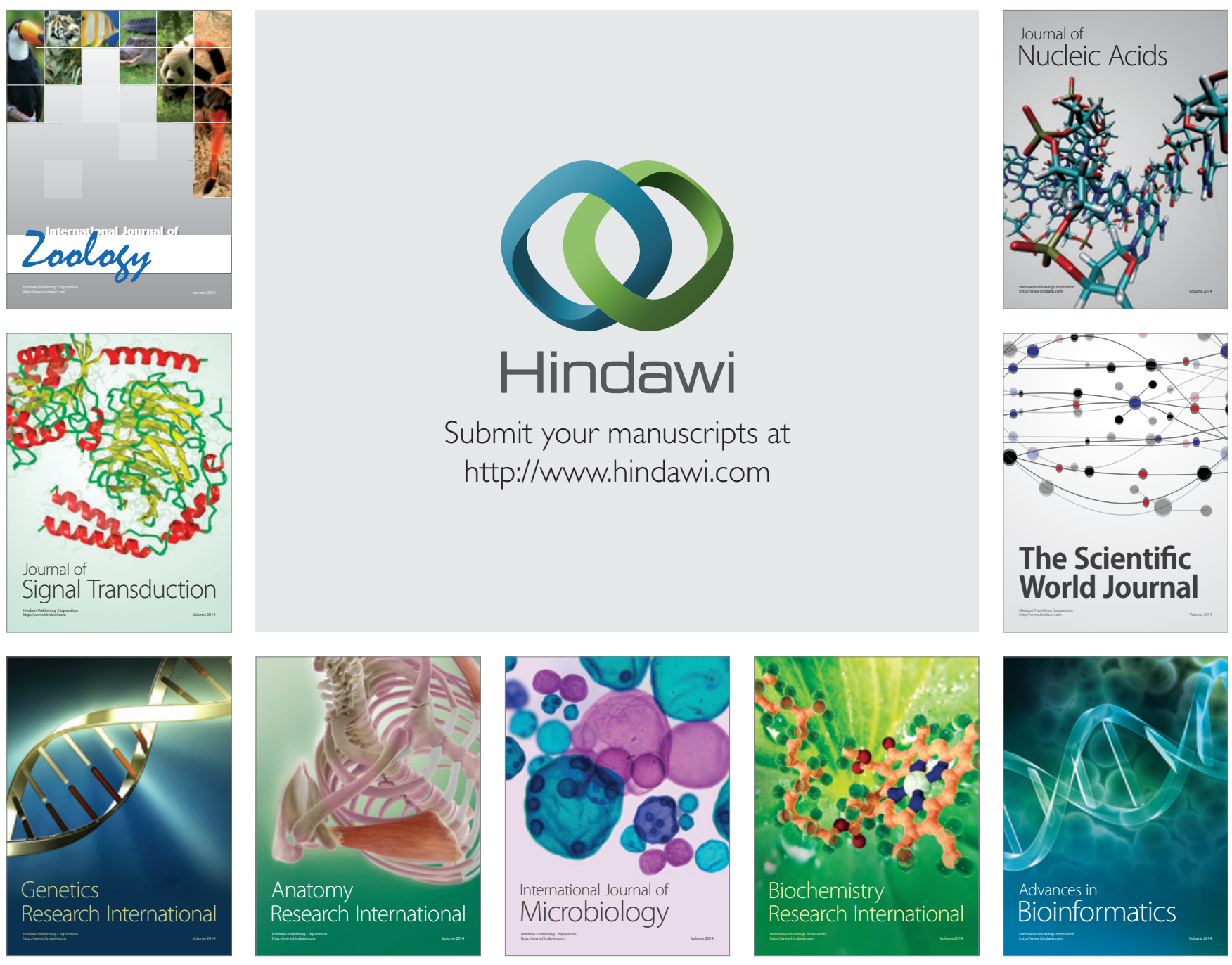

The Scientific World Journal
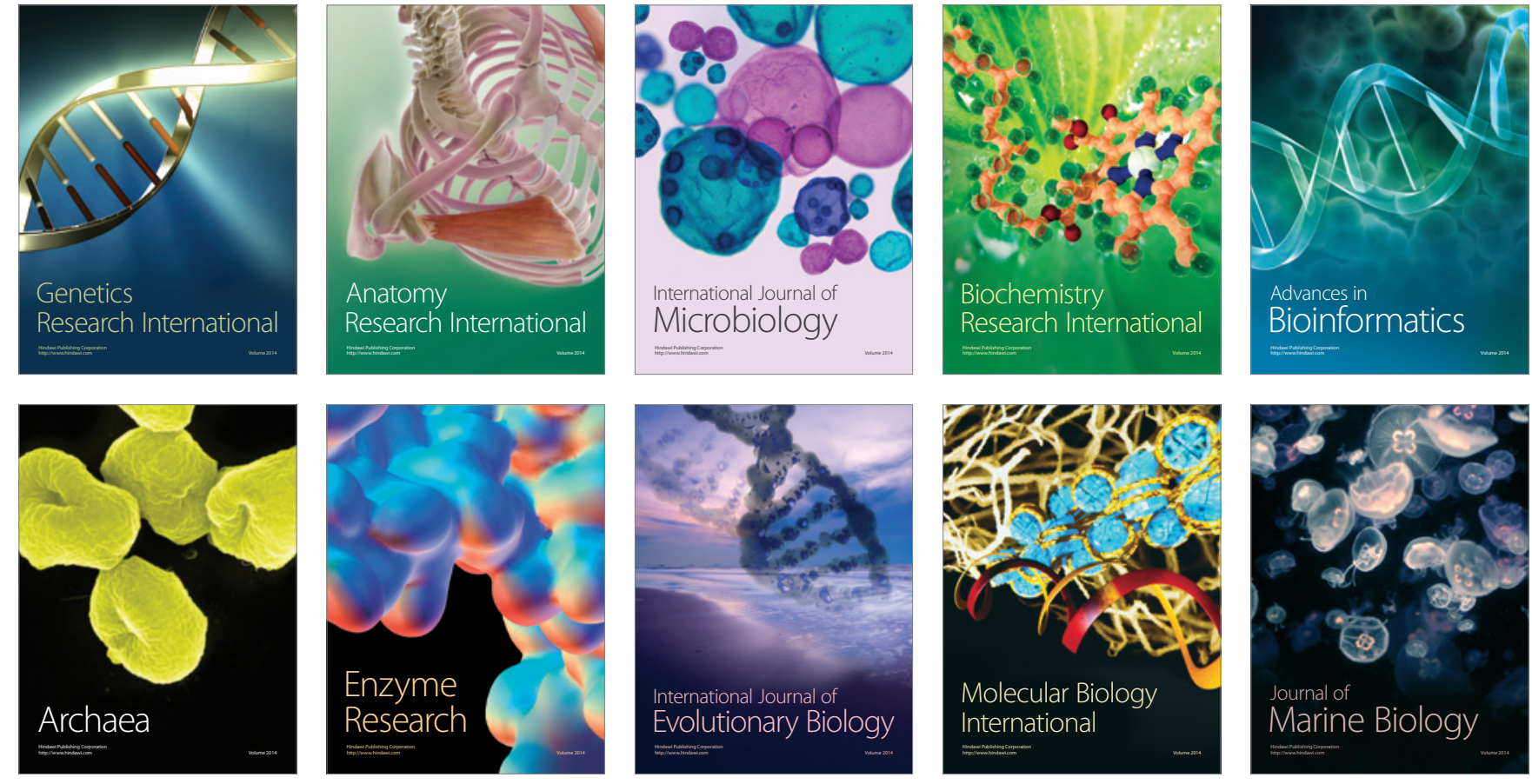